\title{
The effects of gamified customer benefits and characteristics on behavioral engagement and purchase: Evidence from mobile exercise application uses
}

\begin{abstract}
This study investigates how gamified customer benefits (epistemic, social integrative, and personal integrative) and customer characteristics (age and experience) influence marketing outcomes, behavioral engagement and purchase, in exercise context. Using a unique data set of exercise and purchase history created by 5,072 smartphone users over three years in South Korea, this study finds that although all three customer benefits are positively associated with marketing outcomes, personal and social integrative benefits are the best predictors for engagement and purchase, respectively. Furthermore, the effects of gamified customer benefits on marketing outcomes vary by age and experience, showing the importance of epistemic and personal integrative benefits to older and less experienced customers and social integrative benefits to younger and experienced customers. This study not only explores the long-term effects of gamification on behavioral outcomes but also examines the feasibility of successfully implementing the gamification benefit proposition strategy for superior marketing outcomes.
\end{abstract}

Keywords: gamification; customer benefits; customer characteristics; engagement 


\section{Introduction}

Due to increasing interest in personal health, 55 million and 141 million American people participate in fitness/health clubs and outdoor physical activities, respectively (Outdoor Industry Association, 2015). Recently, the mobile apps market has seen a proliferation of healthcarerelated apps, and exercise and fitness apps are the most popular, accounting for $39 \%$ of mobile health apps (Aitken and Gauntlett, 2013). Exercise apps include a range of features for monitoring and managing one's own exercise records, the so-called "quantified self" (Wolf, 2009) or 'personal informatics' tools, for collecting, and reflecting upon information about the self (Li, Dey, and Forlizzi, 2010). To increase engagement, exercise apps adopt gamified features because health gamification can support behavior change (King et al., 2013; Munson et al., 2015; Pereira et al., 2014). For example, Nike+ tracks measured physical exercise into "NikeFuel points" which later can be used in competitions with friends; and Zombies, Run! motivates runners via wrapping runs incorporated into an audio-delivered story of surviving a Zombie apocalypse.

Research confirms why gamification of exercise apps is relevant to health behavior and indeed why online games are valuable (Hamari and Keronen, 2017). According to selfdetermination theory, the desire to engage in a particular behavior is based upon intrinsic and extrinsic motives (Calder and Shaw, 1975). Intrinsic motives lead to rewards that are internal to the individual whereas extrinsic motives lead to external rewards or punishment (Deci and Ryan, 1985). In the exercise context, gamified exercise apps can motivate initiation and performance of health behaviors extrinsically - via social recognition and accumulation of material gains (e.g. rewards), and intrinsically - via personal goals and enjoyment (Davis and Cowles, 1991). 
Further, as greater audiences play, game design elements become more appealing (Hamari and Keronen, 2017; King et al., 2013). Gamified exercise apps practically encompass all trackable everyday activities, whereas serious health games require people to dedicate time and space to their engagement (Munson et al., 2015). However, engaging with gamified apps can contribute to well-being by generating positive experiences in terms of basic psychological need satisfaction and emotions, such as engagement or accomplishment (McGonigal, 2011; Pereira et al., 2014). Indeed, through implementing customer-geared gamification elements, app providers can enhance customer experiences and motivate them to continue physical exercise.

Yet, with these promises in mind, questions remain such as how app providers should implement gamification in sustainable and profitable ways: and specifically, which gamification benefit proposition, especially non-monetary benefits, can strengthen deeper behavioral engagement, and facilitate subsequent product purchase? And, further, how may the effects of gamified customer benefits on marketing outcomes vary by customer characteristics? These questions are relevant as research needs to ascertain how non-monetary benefits (and financial rewards) impact marketing outcomes (Hofacker et al., 2016). Further, prior research has indicated effects of gamification mainly related to engagement behaviors (Harwood and Garry, 2015), and effectiveness of gamification may vary across different customer traits (Hofacker et al., 2016).

The objectives here are to explore empirically, how gamified customer benefits affect two marketing outcomes: engagement behavior via continued use of an exercise app and purchase behavior of exercise-related products; and how customer characteristics moderate the effects of gamification benefits on marketing outcomes. To identify different types of gamified customer benefits, we employ the "uses and gratifications" model (Katz et al., 1974), a framework widely 
used in the communication field. Researchers have used this model to examine how different benefits shape media-usage behavior (Palmgreen, 1984) and inculcate customer participation in value co-creation (Nambisan and Baron, 2009). Here, we propose that epistemic, social integrative, and personal integrative benefits will shape actual customer engagement and purchase behaviors in an exercise app environment. As customer-related moderators, we employ two customer traits: age and experience. Research shows that the effects of technology design on customer acceptance depend on these traits (Venkatesh et al., 2012), and the importance of different game features vary in older versus young customers (Park and Lee, 2011).

To address these issues, we constructed a data set of exercise and purchase activities from 2013 to 2015 (three years) created from 5,072 smartphone users who installed 'Tranggle' South Korea's most popular exercise app. It enabled us to offer an accumulated set of indices that benchmarks not only customers' exercise but also their product purchase behavior. To our knowledge, this is the first research to examine the feasibility of successfully implementing the gamified benefit proposition strategy while taking into account promoting customer exercise engagement (i.e., public health) and product purchases (i.e., firm benefit). Following is the theoretical background for the study on gamified exercise service and several research hypotheses about the effectiveness of gamified customer benefits and customer characteristics. We then report an empirical study that tests the hypotheses. Lastly, based on the findings, we provide theoretical and managerial implications.

\section{Literature review and hypotheses}

\subsection{Exercise motivation and gamification}


Extant research shows that gamification i.e., the use of game design elements in non-game contexts (Deterding, 2015), increases customer benefits and encourages benefit-creating behaviors such as loyalty, customer engagement, and motivation (Blohm and Leimeister, 2013). Admittedly, this does represent a limited view relative to the needs of our research and we acknowledge that more time could be spent on definitional issues (Morschheuser et al., 2017). In an exercise context, activity trackers and smartphones are equipped with powerful sensing, processing, storage, and display capacities, so they provide platforms to extend a game layer to everyday exercise behaviors (King et al., 2013). Like games, gamified exercise apps employ a broad range of game design elements such as generation of points, badges, leaderboards, and of course social interaction. Recent health studies have mainly focused on rewards, accounting for 84\% (16 of 19 studies between 2012 to 2016), and indicate strong evidence that reward drive health behavior (Johnson et al., 2016). For example, rewards such as points and achievements are associated with improvement in desire to exercise (Hamari and Koivisto, 2015), or increased physical activity and sense of empowerment, for example, among rheumatoid arthritis patients (Allam et al., 2015). Riva et al. (2014) note the positive impact of points with leaderboards on health outcomes such as lowered pain burden and increased exercise.

The idea of rewards from gamified products leads to motivation and its categories. Use of financial rewards is based on extrinsic motivation. Such extrinsic activity is done for an outcome (e.g., material gains) separable from the activity itself (e.g., exercise), which may thwart autonomy need satisfaction and give rise to the experience of unwillingness and tension (Deci and Ryan, 2012). Contrariwise, intrinsically motivated activity is done for its own sake, which satisfies basic psychological needs for autonomy, competence, and relatedness, giving rise to the 
experience of willingness and enjoyment (ibid). It is demonstrable that intrinsic motivations offer more advantages than extrinsic motivations with regard to health behavior (Fortier et al., 2012; Patrick and Williams, 2012). However, Blohm and Leimeister (2013) argue that this effect may occur with game-specific symbolic rewards (e.g., points or badges) because their collection helps

show progress toward personal goals, facilitate social interaction with peers, and may function as an instrument of social recognition within a community. Therefore, these rewards, i.e., points and badges, or so called symbolic capital, serve as both extrinsic and intrinsic motivations (Hofacker et al., 2016).

\subsection{Research model for exercise gamification}

Gamification offers opportunity to generate non-monetary benefit propositions for consumers, in addition to the reward benefits (Hofacker et al., 2016). In order to identify such non-monetary benefits, we apply the uses and gratifications $(U \& G)$ framework, which proposes that media users are goal-oriented and proactively select media to obtain different types of benefits (Katz, Blumler, and Gurevitch, 1973). That is, media users seek out a particular media source to gratify their needs and wants because there are alternative choices for their gratifications. As the $U \& G$ theory assumes that people obtain benefits from their use of a new media (Weibull, 1985), it has been applied to new media contexts including the Internet (Stafford, Stafford, and Schkade, 2004), social media (Malik, Dhir, and Nieminen, 2016) and various gaming services, such as online games (Wu, Wang, and Tsai, 2010), social mobile games (Wei and Lu, 2014) and mobile augmented reality games (Rauschnabel, Rossmann, and tom Dieck, 2017). If users obtain benefits from the usage of a new media (i.e., gratifications), they 
will use the new media more frequently, leading to an increase in users' continuance use intention (i.e., engagement) with the new media (Weibull, 1985).

The U\&G concept moves from exploring what media does to users toward what users do with media (Palmgreen, Wenner, and Rosengren, 1985). That is, the gratification processes take place within the interactions among media structures, social structures and the individual characteristics of media use (Palmgreen, Wenner, and Rosengren, 1985; Weibull, 1985). Customer benefits derived from media usage can be classified into three categories (Katz, Blumler, and Gurevitch, 1974; Nambisan and Baron, 2009): (1) epistemic benefits, such as information acquisition and increasing users' understanding of the environment; (2) social integrative benefits that relate to strengthening users' relationships with others; and (3) personal integrative benefits that relate to strengthening the-credibility and social status among others. Here, the primary focus is on exercise app users' behavior and on how deffferent types of gamified customer benefits shape the users' engagement and purchase behavior. Whereas prior U\&G studies have focused on how individuals use media (Rubin, 2002), exercise apps indicate dynamic audience activities compared to traditional media (Gerlich et al., 2015; Levy and Windahl, 1984). Due to the behavioral nature of exercise apps, the three benefit categories (epistemic, social integrative, personal integrative) can be interpreted in the context of the present study.

\section{[Insert Figure 1 about here]}

As shown in Figure 1, the U\&G framework provides three broad types of benefits that individuals can derive from exercise app uses. First, epistemic benefits, interacting with media, relates to skill development, information acquisition, and environmental knowledge and understanding (Nambisan and Baron, 2009). An example can be downloading or acquisition of 
exercise-related specific knowledge from an exercise app database. Second, social integrative benefits, interacting with others through media, relates to strengthening consumer ties with other relevant peers (Nambisan and Baron, 2009). An example includes sharing personal exercise experience with other peers via an online review board. Finally, personal integrative benefits, interacting with oneself, relates to perceived gains in reputation, status or achievement of a sense of self-efficacy (Katz, Blumler, and Gurevitch, 1974). Self-efficacy reflects a person's belief in their ability to overcome difficulties inherent in performing a specific task (Bandura, 1977). An example includes continuing to do exercises regularly over a long period.

Thus, by leveraging the U\&G framework, we identify a cogent set of three benefit categories that can potentially drive customer engagement in exercise app use and influence subsequent product purchase. While gamified customer benefits can provide motivation to maintain or increase exercise, such outcomes may not be sustained over time (Thorsteinsen, Vitters $\varnothing$, and Svendsen, 2014). In other words, responses (i.e., engagement and purchase) to gamification benefits are not necessarily consistent for all types of exercise app users (Reynolds, Sosik, and Cosley, 2013), and not all types of gamified benefits help users achieve their exercise goals or positively impact user adoption (Spillers and Asimakopoulos, 2014).

Here, we employ age and experience (two elements of customer characteristics) as moderating variable for the relationship between gamified customer benefits and marketing outcomes. Research shows that online gamers' consumption benefits on game items (Park and Lee, 2011) and/or digital gamers' responses to product advertising (Bittner and Schipper, 2014) may vary across different age groups. In addition, customers may show different dependence on facilitating conditions - consumers' perception of the resources and support to perform a 
behavior (Venkatesh et al., 2003) - across different levels of experience (Venkatesh, Thong, and $\mathrm{Xu}, 2012)$.

To investigate gamification factors that drive marketing outcomes, we examine the relationship between various antecedents and behavioral engagement of continuing the exercise app use and purchase of exercise-related products. Customer benefits of gamification are divided into three categories (i.e., epistemic, social integrative, personal integrative) and customer characteristics include age and experience. Furthermore, direct and indirect relationships between gamified customer benefits and characteristics and marketing outcomes are examined. Figure 2 presents the research model and hypotheses.

[Insert Figure 2 about here]

\subsection{Hypotheses for exercise gamification}

Epistemic benefits denote the perceived utility acquired from a product's capacity to arouse curiosity, provide novelty, and/or satisfy a desire for knowledge (Sheth, Newman, and Gross, 1991). Exploratory, novelty seeking and variety seeking consumption behaviors, as examples of epistemic benefit pursuit, tend to activate product search, trial, and switching behaviors (Hirschman, 1980). Such information-seeking motive is more pronounced in the usage of Internet and digital content such as online forums (Nambisan and Baron, 2009) and video games (Khang, Kim, and Kim, 2013). In an exercise app context, epistemic benefits entail curiosity for new content and knowledge gained through testing new exercise-related services. For example, when a novice mountain climber installs a mobile exercise app, they can browse various climbing routes in the focal app, download a most preferred route and use it during climbing. 
Such epistemic benefits can be created through the cognitive benefits of skill development, information acquisition, and learning (Nambisan and Baron, 2009) that expands users' knowledge and expertise in exercise (Hofacker et al., 2016). Research shows that epistemic benefits are more relevant when people seek hedonic rather than utilitarian benefits (Cotte et al., 2006). It is proposed that epistemic benefits will motivate customers to continue using the gamified exercise app and further drive them to purchase exercise-related products offered by the focal app. Therefore:

H1: An increased level of epistemic benefits will lead to an increased level of (a) behavioral engagement and (b) purchase.

Social integrative benefits denote benefits deriving from social and relational ties that develop over time among participating community actors (Nambisan and Baron, 2009). Such relationships provide a range of customer benefits, including an enhanced sense of belongingness (Kollock, 1999) or recognition_-referring to social feedback customers receive on their behaviors (Nambisan and Baron, 2009). Prior studies on gaming services demonstrate the importance of social integrative benefits in market outcomes. For instance, social interaction, such as making friends and sharing experiences and information with each other, is not only effective in increasing gaming time (Kaczmarek et al., 2017), but also driving game players to participate in online games ( $\mathrm{Wu}, \mathrm{Wang}$, and Tsai, 2010). In the exercise context, research also indicates that social integrative benefits have a positive impact on how much people are willing to do exercise as well as their attitudes and willingness to use gamification services (Hamari and Koivisto, 2015). Therefore, we hypothesize: 
H2: An increased level of social integrative benefits will lead to an increased level of (a) behavioral engagement and (b) purchase.

Personal integrative benefits denote gains in reputation or status and achievement of a sense of self-efficacy (Katz, Blumler, and Gurevitch, 1974). Self-efficacy reflects a person's belief in their ability to overcome difficulties in doing exercises (Bandura, 1977) and represents a good predictor of health behavior change (AbuSabha and Achterberg, 1997). People may be high or low in self-efficacy dependent on the exercise behavior (AbuSabha and Achterberg, 1997). If people have high self-efficacy in exercise, they tend to conduct exercises regularly for a longer period than those with low self-efficacy. Gamified exercise apps sit at the intersection of persuasive technology (e.g., features that drive targeted behaviors), serious games (e.g., intrinsically motivating elements), and personal informatics (e.g., tracking of individual behaviors) (Cugelman, 2013). Gamification literature finds that rewards in the form of points, badges, leaderboards are associated with improvements in desire to exercise (Hamari and Koivisto, 2015) and increased physical activity (Allam et al., 2015). Therefore, we posit that personal integrative benefits will motivate customers to continue using the gamified exercise app and further drive them to purchase exercise products, thus hypothesizing:

H3: An increased level of personal integrative benefits will lead to an increased level of (a) behavioral engagement and (b) purchase. 
Customers' responses to gamification benefits are not necessarily consistent for all customer types-of customers (Reynolds, Sosik, and Cosley, 2013) and not all types of gamification benefits help users achieve exercise goals (Spillers and Asimakopoulos, 2014). The effects of technology design to enhance gamification may depend on individual customer age and experience (Venkatesh et al., 2003; Venkatesh, Thong, and Xu, 2012). Psychology research indicates that, among age, gender and race/ethnicity, only age significantly moderates the impact of psychological factors (e.g., mood) on exercise outputs (Annesi, 2013). Concerning the role of age in technology adoption, research indicates that younger users, when deciding on use intentions, emphasize usefulness of the technology more than older users (Venkatesh et al., 2003). Furthermore, older users may experience more computer anxiety than younger users, so perceiving their use skills of digital technologies as lower (Chung et al., 2010). In terms of physical activity with gamified services, Kaczmarek et al. (2017) indicate that older participants of mobile augmented games (e.g., Pokémon Go) tend to spend more time playing the games, yet virtual engagement does not translate into more physical activity. This study is consistent with a fact that physical activity decreases with age (Hallal et al., 2012). On the contrary, younger participants typically spend more time in the usage of new media (Rideout, Roberts, and Foehr, 2005). In addition, younger customers have higher intentions to purchase gamified products than older customers because they judge them as more useful and perceive more enjoyment (Bittner and Schipper, 2014). Therefore, we hypothesize:

H4: Age will moderate the effect of gamified customer benefits on (a) behavioral engagement and (b) purchase, such that the effect will be stronger among younger customers. 
Experience can lead to greater product familiarity and better knowledge structures facilitate customer learning, thus reducing customer dependence on external resources and support (Alba and Hutchinson, 1987). On the contrary, customers with less experience or familiarity will depend more on facilitating conditions - customers' perceptions of the resources and support available to perform a behavior (Notani, 1998; Venkatesh et al., 2003). Therefore, less experienced beginners respond positively to gamified features incorporated into the exercise activities than more experienced experts (Reynolds, Sosik, and Cosley, 2013), thus hypothesizing:

H5: Experience will moderate the effect of gamified customer benefits on (a) behavioral engagement and (b) purchase, such that the effect will be stronger among less experienced customers.

\section{Methodology}

\subsection{Data collection and sample}

To test the hypotheses, we obtained longitudinal data of exercise and purchase behavior from Tranggle (www.tranggle.com), the largest mobile exercise app provider in South Korea, whose monthly active users wereas about one million (as of June 2017). This exercise app uses the global positioning system (GPS) in order to track the specific geographic route of an outdoor exercise event. Therefore, the data did not include the app users' indoor exercise behavior such as running exercises in a gym. Like Apple Health and Google Health, this exercise app enables 
users to track and record the details of each exercise activity by type (i.e., walking, running, cycling, hiking, roller-blading), in terms of time, speed, location, and distance. This app offers gamification elements such as points, badges, leaderboard and social interaction throughout its usage. Specifically, when a user turns on the exercise app and commences exercise, the app announces summarized information of the exercise movement at every 500-meter location. Such narration not only stimulates the app user to speed up or go further in this particular exercise but also lowers boredom. After an exercise is ended, the app provides a record-certifying badge with a visual identification and reveals ranking information to peers. In addition, the app offers certain points or mileage by reflecting repeated interaction information as a user masters skills such as actions (exercise itself, uploading own route information), objects (type of exercise), feedback (badges), and challenge (e.g. mountain slope) (Deterding, 2015). Once a certain number of points are accumulated, the user class will be promoted and there are 73 classes. Therefore, the final number of points or mileage represents the level of his/her behavioral engagement in the exercise app use.

In addition to gamification elements, this app provides actual data related to app usage benefits and customer characteristics. First, the app stores over 10 million routes which have been uploaded by app users, the so-called crowdcreating and -solving system (Morschheuser et al., 2017), so any user can download a particular route from a specific destination to an end point among various alternatives (i.e., epistemic benefits through information acquisition). Second, app users can share their experiences online such as exercise comments, photos, know-how, and recommendations (i.e., social integrative benefits through others interaction). Third, as a "quantified self" (Wolf, 2009) or "personal informatics" tool (Li, Dey, and Forlizzi, 2010), the app tracks and records all exercise distances walked, run, cycled, climbed, and/or rollerbladed 
since app installation (i.e., personal integrative benefits showing status or accomplishment of exercise-related self-efficacy). Finally, the app collects information about individual characteristics such as age, gender and residential address.

Along with exercise-related information, this app also enabled us to collect app users' purchase history (i.e., quantity and expenditure) due to the in-app commerce functionality. Because we attempted to investigate how gamified benefits affect purchases, we focus on app users who have purchased exercise product(s) at least once for the observation period. We found that, as of December 2015, the app operator was selling 1,093 products such as running/hiking shoes, exercise clothes, and other exercise equipment. By combining the exercise and purchase behavioral data, we construct a longitudinal dataset of exercise and purchase activities created by 5,072 users (out of 1 million registered app users) who had purchased products at least once during the three-year period (January 2013 to December 2015).

\subsection{Variables and equation}

Due to our focus on the marketing outcomes of gamified exercise app, we choose two dependent variables: engagement and purchase. Notably, customer engagement reflects the cognitive, emotional and behavioral outcomes that are related to an interactive experience (Brodie et al., 2011). However, we focus on the behavioral dimension of customer engagement in a customer-to-firm relationship because the behavioral manifestations may result from motivational drivers such as gamified customer benefits (van Doorn et al., 2010). In this study, engagement behavior (engagement) is measured by the number of accumulated points or mileage through using the focal exercise app and doing exercises during the observation period (Harwood 
and Garry, 2015). In addition, the gamified customer benefits and engagement behavior may impact market outcomes (Harwood and Garry, 2015). Regarding the purchase variable, we identify two sub-variables: (1) purchase quantity measured by the number of products purchased (sales) and (2) purchase expenditure measured by the dollar amount of purchased products (revenue). We use the revenue model for robustness check (Hofacker et al., 2016).

The main independent variables comprise three customer benefits that are derived from the app users' longitudinal behaviors rather than psychological measures. This view is in line with the theoretical view of service-dominant logic (Vargo and Lusch, 2008) where the benefits of an exercise app service emerges from the voluntary user-driven interaction between the user and the app service. In this vein, any app service can be seen as a set of affordances - actionable properties between a service and a user (Gibson, 1977) - intended to enable the exercise app user to realize the service-related benefits. Furthermore, behavioral measures of using the gamified customer benefits, not the gamification mechanism itself, can better explain the exercise app users' engagement and purchase behaviors (Hamari, 2013). As such, behavioral measures for three gamified customer benefits are applied in this study.

Specifically, first, epistemic benefits are measured by the number of exercise route software downloads from the focal exercise app database. This measure represents the level of epistemic benefits which a specific exercise app user seeks. For example, an unskilled mountain climber may download a specific mountain route software from the database whenever he/she climbs a new mountain. Second, social integrative benefits are measured by the number of online postings, including comments, recommendation, and photo sharing. This measure indicates how a specific app user intends to strengthen his/her tie with other peers by sharing personal exercise experiences via online community. Finally, personal integrative benefits are measured by the 
meter of accumulated exercise distances recorded by a specific app user. This measure represents the level of achievement of a sense of self-efficacy because the accumulated distances are the final outcomes from his/her long-term exercise efforts.

As the moderating variables, we use two customer characteristics: age measured by the actual age ranging from 15 to 78 and experience measured by the number of days which have passed since the focal exercise app was downloaded (Kim and Malhotra, 2005; Venkatesh et al., 2003). Next, we control for three elements that may influence the marketing outcomes. Exercise duration is measured by the average exercise distance in meters per activity (Peetz, Buehler, and Britten, 2011). Exercise duration (e.g., long versus short distances per activity) may affect exercise intentions and behavior (Peetz, Buehler, and Britten, 2011). Habit, measured by average exercise frequency per day (Venkatesh, Thong, and Xu, 2012), can be positively correlated with gamified service (Lee and LaRose, 2007). Variety is measured by the number of exercise types per user ranging from 1 to 5 . A recent health research indicates that different types of exercise is contributed to the variability in energy expenditure and time spent (Drenowatz et al., 2014).

For the analysis, we develop a multiple regression model to investigate how gamification benefits influence marketing outcome of customer i (i.e., main effects) and customer characteristics of customer i affect marketing outcome indirectly (i.e., interaction effects). The empirical model is as follows:

$Y_{i}=\beta_{0}+\beta_{1}$ Epistemic benefits ${ }_{i}+\beta_{2}$ Social integrative benefits $i_{i}$

$+\beta_{3}$ Personal integrative benefits $_{i}+\beta_{4}$ Age $_{i}+\beta_{5}$ Experience $_{i}$

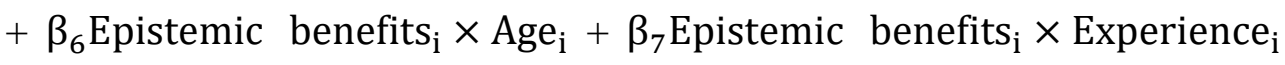

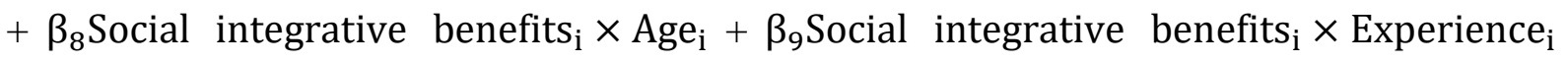


$+\beta_{10}$ Personal integrative benefits $_{\mathrm{i}} \times \mathrm{Age}_{\mathrm{i}}$

$+\beta_{11}$ Personal integrative benefits $_{i} \times$ Experience $_{i}$

$+\beta_{12}$ Exerise duration $_{\mathrm{i}}+\beta_{13}$ Habit $_{\mathrm{i}}+\beta_{14}$ Variety $_{\mathrm{i}}+\varepsilon_{\mathrm{i}}$

where $Y_{\mathrm{i}}$ denotes the behavioral engagement (Model A: engagement model) and purchase (Model B: purchase model where engagement variable is added as independent variable) of customer i, $\beta_{n}(n=1,2, \ldots 14)$ refers to the corresponding parameter estimates of independent variables, and $\varepsilon_{\mathrm{i}}$ is the error term of the model.

\section{Results}

\subsection{Descriptive statistics}

Table 1 contains the descriptive statistics and correlation coefficients for the variables. We find that the average age of the participants was 47.86 with a range between 15 and 78 , and they, on average, used the exercise app for approximately 1,066 days (2.92 years) ranging from 730 days ( 2 years) and 1,698 days (4.63 years). Findings indicate that most app users in this sample were relatively old and used the exercise app for a longer period. The average monthly exercise frequency of the app users was 0.07 , ranging from 0 to 3 , and the participants engaged in over 2 types of exercise such as hiking, walking, jogging and bicycling.

[Insert Table 1 about here]

Table 2 further reports the detailed exercise behavior during the observation period. On average, the participants used the exercise app 160 times in total, ranging from 1 to 2,828, and 
4.637 times per month, ranging from 0.02 to 79.52 . The most popular exercise activity was hiking (2.027 times/month), followed by walking (1.472), bicycling (0.898), and jogging (0.237).

[Insert Table 2 about here]

We find that the correlation coefficients among the three independent variables (epistemic benefits, social integrative benefits, and personal integrative benefits) are relatively low, ranging from 0.14 and 0.18 (Table 1). In order to check any multicollinearity concern, we examine variance inflation factors (VIFs) and find that the VIF values ranged from 1.06 to 2.28 , so multicollinearity is not a serious issue in the final model.

Finally, we use Bayesian estimations for model parameters with diffuse conjugate priors via the Markov Chain Monte Carlo (MCMC) simulation method. 10,000 draws of each chain are implemented for the burn-in period with convergence tests and 10,000 draws from each of the two chains are used for the estimation of all model parameters. Full description on priors and posterior joint distributions can be obtained from authors upon request.

\subsection{Hypothesis testing}

The empirical results regarding the effects of gamified customer benefits on engagement (Model A) are summarized in Table 3. First, three customer benefits (epistemic, social integrative, and personal integrative) are positively associated with exercise engagement ( $\beta_{1}=0.265, \beta_{2}=0.050$, and $\beta_{3}=0.436$, respectively), in support with H1a, H2a, and H3a. Second, while age is positively related to exercise engagement $\left(\beta_{4}=0.009\right)$, the result also suggests that the effect of epistemic and personal integrative benefits will be stronger among older users ( $\beta_{6}=0.024$ and $\beta_{10}=0.023$, respectively) but not with social integrative benefits. These results do 
not support H4a. Finally, less experience not only drives more engagement directly but also accelerates users with greater epistemic and personal integrative benefits to engage in the gamified exercise $\left(\beta_{7}=-0.179\right.$ and $\left.\beta_{11}=-0.032\right)$, supporting $\mathrm{H} 5 \mathrm{a}$.

From the purchase perspective, the empirical results provide the effects of gamified customer benefits on purchases in terms of sales volume (Model B1) and revenue (Model B2), as shown in Table 4 and Table 5, respectively. First, epistemic and social integrative benefits are positively associated with exercise-related product sales $\left(\beta_{1}=0.089\right.$ and $\beta_{2}=0.164$, respectively) and product revenue ( $\beta_{1}=0.065$ and $\beta_{2}=0.146$, respectively). Two models confirm $\mathrm{H} 1 \mathrm{~b}$ and $\mathrm{H} 2 \mathrm{~b}$, but not H3b. Second, although age is positively related to purchases (Model B1: $\beta_{4}=0.068$ and Model B2: $\beta_{4}=0.044$, respectively), the effect of social integrative benefits will be stronger among younger customers (Model B1: $\beta_{8}=-0.080$ and Model B2: $\beta_{8}=-0.070$, respectively) but not with epistemic and personal integrative benefits. These results partially support H4b. Finally, the results report that the effect of epistemic benefits on sales volume will be stronger among less experienced customers (Model B1: $\beta_{7}=-0.052$ ), but the effect of social integrative benefits among more experienced customers (Model B1: $\beta_{9}=0.073$ ). However, the results of Model B2 indicate that the effect of social and personal integrative benefits on revenue will be stronger among more experienced customers $\left(\beta_{9}=0.050\right.$ and $\beta_{11}=0.031$, respectively). Thus, the results partially support H5b.

[Insert Table 3, Table 4, and Table 5 about here]

\section{Discussion and Implications}


In this paper, we empirically examine which gamified customer benefits and customer characteristics influence marketing outcomes of an exercise app. We investigate which gamified benefits (epistemic, social integrative, or personal integrative) and customer characteristics (age and experience) are associated with engagement behavior in the gamified exercise app and purchase behavior of exercise-related products. While the overall results correspond to the extant literature and enhance the theoretical foundations, this study provides unique findings for gamification research and practitioners.

\subsection{Discussion}

Concerning epistemic benefits, we find that epistemic benefits not only motivate people to continue exercises for a long period but also drive them to purchase more exercise products. People tend to gather exercise-related information (e.g., specific trekking routes) through the use of the exercise apps, and such information-seeking behavior is shown to be an important factor driving customer engagement and purchase behaviors. The results seem to be in line with prior studies that information-seeking motive drives the usage of video games (Khang, Kim, and Kim, 2013) and virtual customer environments (Nambisan and Baron, 2009). The exercise-related information and knowledge can be considered as a public good where community users collectively contribute to its provision and all users may access knowledge provided. When knowledge is considered a public good, knowledge exchange is motivated by moral obligation and community interest rather than by narrow self-interest (Wasko and Faraj, 2000). Therefore, our findings provide empirically derived evidence on the effectiveness of epistemic benefits that 
exercise information-seeking behavior activates more behavioral engagement in the continued exercises and more purchases in exercise products.

Second, this study indicates that social integrative benefits play a significant role in motivating people to continue their exercises and purchase products, which is in line with findings in the gaming context. Research has shown that social motivation is effective in increasing the playtime of online games (Wu, Wang, and Tsai, 2010) and augmented reality games (Kaczmarek et al., 2017). This finding is quite meaningful in the gamification study because prior studies focus more on the game-specific symbolic rewards such as points or badges (Blohm and Leimeister, 2013), with less attention to the importance of various forms of online social interaction in the form of posting, recommendation and other experience-sharing (Nambisan and Baron, 2009). Therefore, gamified products that encourage social interaction may create an atmosphere of camaraderie and facilitate interactions with the brand and other customers (Hofacker et al., 2016).

Third, we also find that personal integrative benefits are the most pronounced customer benefits to drive greater exercise engagement. In this study, personal integrative benefits were operationalized as the accumulated exercise distance an app user creates for a long period. Our finding suggests that people with high levels of self-efficacy for exercise behavior have been shown to exercise more frequently (Bandura, 1977), resulting in more accumulated exercise distance than people with low levels of self-efficacy. According to goal orientation theory of achievement motivation, variations in exercise behavior are not necessarily a result of high or low absolute amounts of motivation, but are a manifestation of the qualitatively different goals adopted by individuals (Roberts, 2001). The personal integrative benefits are similar with the gaming achievement motive because achievement involves the desire to gain power, gather 
valuable performance points, and compete with other gamers (Hartmann and Klimmt, 2006). Previous studies have shown that the achievement motive is one of major initiative motivations for continuing playing online games (Wu, Wang, and Tsai, 2010) and augmented reality games (Kaczmarek et al., 2017).

Finally, the results indicate that the effects of gamified customer benefits on marketing outcomes vary by age and experience. Age itself has positive, significant association with both engagement and purchase behaviors but does have mixed moderating effects on the relationship between gamified customer benefits and market outcomes. Specifically, this study finds that age has a positive moderating effect on the effect of epistemic and personal integrative benefits on exercise engagement but a negative moderating effect on the effect of social integrative benefits on exercise product purchases. This finding is different from previous research suggesting that older users of mobile augmented games spend less time engaging in physical activity although spending more time playing the games (Kaczmarek et al., 2017). A situation of using a gamified exercise app seems different from a situation of using physical activity-based mobile games. In exercise context, older people tend to seek exercise-related information actively and have high self-efficacy in their exercise app usage, which seems to drive them to exercise continuously, than do younger people. Conversely, this study demonstrates that social integrative benefits tend to encourage younger people to purchase exercise products (Bittner and Schipper, 2014), although having no relationship with their exercise engagement.

Furthermore, experience has not only a direct effect on engagement but also a moderating effect between gamified customer benefits and market outcomes. This study finds that less experienced customers with an exercise app become engaged in more exercises as they obtain exercise-related information (i.e., epistemic benefits) and high level of self-efficacy (i.e., 
personal integrative benefits). This finding is in line with prior studies indicating that gamified features have positive impacts on exercise behavior only for less experienced beginners than more experienced experts (Reynolds, Sosik, and Cosley, 2013). Interestingly, this study indicates that as exercise app users gain experience, social and personal integrative benefits drive the experienced users to purchase exercise products. That is, personal integrative benefits motivate beginners to engage in more exercises but experts to consume more products. This contrary finding can be explained by the research method, for example, the previous researchers mainly examined the gamification effect on instantaneous or short-term behaviors (Harwood and Garry, 2015) or behavioral intentions (Bittner and Schipper, 2014). However, this study incorporates actual behaviors from a long-term perspective, showing the differential effectiveness of gamified customer benefits depending on the type of market outcome (i.e., engagement versus purchase).

\subsection{Implications}

As the first major theoretical contribution of this study, we provide an extensive model of the gamified customer benefits that drive the customer engagement and purchase behaviors in the exercise app context. The empirical study identifies several theoretical mechanisms that go beyond traditional U\&G method in the gaming context. Specifically, most existing frameworks focus on perceptual or psychological measures of gaming motivations such as immersion, socializing, and achievement (Kaczmarek et al., 2017; Yee, 2006). Our research extends the prior literature on gamification from two aspects. One_- is, this study provides an understanding of the behavioral manifestations on how gamified benefits drive customer engagement and purchase behaviors (van Doorn et al., 2010). It reflects the behavioral nature of exercise apps in 
the model, which is different from traditional media (Gerlich et al., 2015; Levy and Windahl, 1984). The other is, gamified benefits can be explained by the three customer motives for playing physical activity-based mobile games such as Pokémon Go (Kaczmarek et al., 2017; Yee, 2006): (1) immersion motive including the information-seeking in the exercise app (i.e., epistemic benefits), (2) social motive including interaction with other users (i.e., social integrative benefits), and (3) achievements motive focusing the long-term exercise efforts with the exercise app (i.e., personal integrative benefits).

Second, while most existing literature uses single and intentional dependent variables (e.g., intention to use), this study incorporates two behavioral dependent variables, such as engagement behavior (i.e., exercise amount) and purchase behavior (i.e., quantity and expenditure). The behavioral dimensions of market outcomes are crucial for firms to understand specific drivers of both engagement and financial target variables (Marchand and Hennig-Thurau, 2013). Especially for exercise apps, understanding why users make in-app purchases on exercise products is highly relevant for app operators because most apps run a freemium business model. This research also provides a meaningful implication to sports brands such as Adidas and Under Armour that recently acquired mobile exercise apps for the utilization of exercise behavioral data (Sawh, 2016). Furthermore, this study can stimulate researchers and practitioners who investigate multiple facets of product engagement behavior, rather than a general intentional market outcome (e.g., willingness to engage and purchase).

Finally, the findings of this study suggest that gamification of exercise apps can lead to positive impacts for public health management, as well as commercial benefit. Prior studies find the positive association of rewards (i.e., personal integrative benefits) with the desire of exercise (Hamari and Koivisto, 2015) or the increased physical activity (Allam et al., 2015). Other studies 
show that rewards drive physical activity only for a short-term period, but not for a long-term period (Maher et al., 2015). This study overcomes the prior studies' limitation, such as the reliance on self-reported data for measuring the impact of gamification. Our model shows that, from a longitudinal perspective, customer engagement is predominantly driven by personal integrative benefits and product purchases by social integrative benefits. Furthermore, this study suggests the importance of customer characteristics such as age and experience incorporated into gamified customer benefits for better market outcomes (Engl and Nacke, 2013). Although older people engage in less physical activity during the gameplay (Kaczmarek et al., 2017), our research finds information-seeking (i.e., epistemic benefits) and self-efficacy (i.e., personal integrative benefits) playing a more important role in motivating older people to continue their exercises than social integrative benefits. In addition, similar with prior finding that lessexperienced users increase the gamification-based exercise activities (Reynolds, Sosik, and Cosley, 2013), this study provides a more nuanced understanding of the importance of epistemic and personal integrative benefits toward less experienced exercisers.

\subsection{Limitations and future research}

While the present research offers important theoretical and managerial implications, we recognize some limitations. First, we operationalized variables based on their own single-item behavioral measures of gamified customer benefits and engagement behavior. Due to the nature and limitation of secondary data collection, variables for three gamified benefits were measured by one item, respectively, which brings an issue of the content validity of the constructs. Future research could adopt a wider range of measures to reduce dependence on single-item measures. 
Furthermore, concerning the measure of engagement, researchers could reflect cognitive and affective dimensions, as well as behavioral outcome (Brodie et al., 2011), and investigate how the gamified customer benefits drive three types of customer engagement differently. Second, because the data were collected from a South Korean exercise app, there mayight be some cultural influences on participants' behavior. As Korean consumers share a group-oriented cultural background (Hofstede, 1980), participants in this sample tend to be motivated to conform to the norms of a group than participants from individualistic cultures (e.g., Western countries) (Yau, 1986). Such a degree of personal and group-oriented attitudes might affect behavioral intentions (Lee and Green, 1991). In order to increase confidence in the gamification in exercise app market, additional research needs to be conducted with participants in different cultures and/or conduct a comparative study among different cultures. Finally, as true for all empirical gamification studies, this study could not take into account all different combination of gamification elements and thus, our findings are specific to a case of mobile exercise app uses. Nevertheless, this empirical research makes an important contribution to the growing literature on gamification. 


\section{References}

AbuSabha, R., \& Achterberg, C. (1997). Review of self-efficacy and locus of control for nutrition- and health-related behavior. Journal of the American Dietetic Association, 97(10), 1122-1132.

Aitken, M., \& Gauntlett, C. (2013). Patient apps for improved healthcare: From novelty to mainstream. IMS Institute for Healthcare Informatics, NJ: Parsippany.

Alba, J. W., \& Hutchinson, J. W. (1987). Dimensions of consumer expertise. Journal of Consumer Research, 13(4), 411-454.

Allam, A., Kostova, Z., Nakamoto, K., \& Schulz, P. J. (2015). The effect of social support features and gamification on a Web-based intervention for rheumatoid arthritis patients: Randomized controlled trial. Journal of Medical Internet Research, 17(1), e14.

Annesi, J. J. (2013). Moderation of age, sex, and ethnicity on psychosocial predictors of increased exercise and improved eating. The Journal of Psychology, 147(5), 455-468.

Bandura, A. (1977). Self-efficacy: toward a unifying theory of behavioral change. Psychological Review, 84(2), 191-215.

Bittner, J. V., \& Schipper, J. (2014). Motivational effects and age differences of gamification in product advertising. Journal of Consumer Marketing, 31(5), 391-400.

Blohm, I., \& Leimeister, J. M. (2013). Gamification: Design of IT based enhancing services for motivational support and behavioral change. Business and Information Systems Engineering, 5(4), 275-278.

Brodie, R. J., Hollebeek, L. D., Jurić, B., \& Ilić, A. (2011). Customer engagement: Conceptual domain, fundamental proposition, and implications for research. Journal of Service Research, 14(3), 252-271.

Calder, B. J., \& Shaw, B. M. (1975). Self-perception of intrinsic and extrinsic motivation. Journal of Personality and Social Psychology, 31, 599-605.

Chung, J. E., Park, N., Wang, H., Fulk, J., \& McLaughlin, M. (2010). Age differences in perceptions of online community participation among non-users: An extension of the technology acceptance model. Computers in Human Behavior, 26(6), 1674-1684.

Cotte, J., Tilottama, G. C., Ratneshwar, S., \& Ricci, L. (2006). Pleasure or utility? Time planning style and web usage behaviors. Journal of Interactive Marketing, 20, 45-57. 
Cugelman, B. (2013). Gamification: What it is and why it matters to digital health behavior change developers. JMIR Serious Games, 1(1), e3.

Davis, C., \& Cowles, M. (1991). Body image and exercise: A study of relationships and comparisons between physically active men and women. Sex Roles, 25(1-2), 33-44.

Deci, E. L., \& Ryan, R. M. (1985). The general causality orientations scale: Self-determination in personality. Journal of Research in Personality, 19(2), 109-134.

Deci, E. L., \& Ryan, R. M. (2012). Self-determination theory in health care and its relations to motivational interviewing: A few comments. International Journal of Behavioral Nutrition and Physical Activity, 9(24).

Deterding, S. (2015). The lens of intrinsic skill atoms: A method for gameful design. HumanComputer Interaction, 30, 294-335.

Drenowatz, C., Hand, G., Shook, R. P., Jakicic, J. M., Hebert, J. R., Burgess, S., \& Blair, S. N. (2014). The association between different types of exercise and energy expenditure in young nonoverweight and overweight adults. Applied Physiology Nutrition Metabolism, 40(3), 211 217.

Engl, S., \& Nacke, L. E. (2013). Contextual influences on mobile player experience - A game user experience model. Entertainment Computing, 4(1), 83-91.

Fortier, M. S., Duda, J. L., Guerin, E., \& Teixeira, P. J. (2012). Promoting physical activity: Development and testing of self-determination theory-based interventions. International Journal of Behavioral Nutrition and Physical Activity, 9(20).

Gerlich, R. N., Drumheller, K., Babb, J., \& De’Arno, D. (2015). App consumption: An exploratory analysis of the uses \& gratifications of mobile apps. Academy of Marketing Studies Journal, 19(1), 69-79.

Gibson, J. J. (1977). The theory of affordances. USA: Hilldale.

Hallal, P. C., Andersen, L. B., Bull, F. C., Guthold, R., Haskell, W., Ekelund, U., \& Lancet Physical Activity Series Working Group. (2012). Global physical activity levels: Surveillance progress, pitfalls, and prospects. The Lancet, 380, 247-257.

Hamari, J. (2013). Transforming homo economicus into homo ludens: A field experiment on gamification in a utilitarian peer-to-peer trading service. Electronic Commerce Research and Applications, 12, 236-245. 
Hamari, J., \& Keronen, L. (2017). Why do people play games? A Meta-Analysis. International Journal of Information Management, 37(3), 125-141.

Hamari, J., \& Koivisto, J. (2015). "Working out for likes": An empirical study on social influence in exercise gamification. Computers in Human Behavior, 50, 333-347.

Hartmann, T., \& Klimmt, C. (2006). Gender and computer games: Exploring females' dislikes. Journal of Computer-Mediated Communication, 11(4), 910-931.

Harwood, T., \& Garry, T. (2015). An investigation into gamification as a customer engagement experience environment. Journal of Services Marketing, 29(6/7), 533-546.

Hirschman, E. C. (1980). Innovativeness, novelty seeking, and consumer creativity. Journal of Consumer Research, 7, 283-295.

Hofacker, C. F., de Ruyter, K., Luire, N. H., Manchanda, P., \& Donaldson, J. (2016). Gamification and mobile marketing effectiveness. Journal of Interactive Marketing, 34, 2536.

Hofstede, G. (1980). Culture's consequences. Beverly Hills, CA: Sage.

Johnson, D., Deterding, S., Kuhn, K. -A., Staneva, A., Stoyanov, S., \& Hides, L. (2016). Gamification for health and wellbeing: A systematic review of the literature. Internet Interventions, 6, 89-106.

Kaczmarek, L. D., Misiak, M., Behnke, M., Dziekan, M., \& Guzik, P. (2017). The Pikachu effect: Social and health gaming motivations lead to greater benefits of Pokémon GO use. Computers in Human Behavior, 75, 356-363.

Katz, E., Blumler, J. G., \& Gurevitch, M. (1973). Uses and gratifications research. Public Opinion Quarterly, 37(4), 509-523.

Katz, E., Blumler, J. G., \& Gurevitch, M. (1974). Utilization of Mass Communication by the Individual. In: The Uses of Mass Communications: Current Perspectives on Gratifications Research, ed. J.G. Blumler, and E. Katz. Beverly Hills, CA: Sage, 19-32.

Khang, H., Kim, J., \& Kim, Y. (2013). Self-traits and motivations as antecedents of digital media flow and addiction: The Internet, mobile phones, and video games. Computers in Human Behavior, 29, 2416-2424.

Kim, S. S., \& Malhotra, N. K. (2005). A longitudinal model of continued IS use: An integrative view of four mechanisms underlying post-adoption phenomena. Management Science, 51(5), 741-755. 
King, D., Greaves, F., Exeter, C., \& Darzi, A. (2013). 'Gamification': Influencing health behaviours with games. Journal of the Royal Society of Medicine, 106(3), 76-78.

Kollock, P. (1999). The economies of online cooperation. In: Communities in Cyberspace, ed. Smith, M., \& Kollock, P. London: Routledge, 220-242.

Lee, C., \& Green, R. (1999). Cross-cultural examination of the Fishbein behavioral intention model. Journal of International Business Studies, 22(2), 289-305.

Lee, D. W., \& LaRose, R. (2007). A socio-cognitive model of video game usage. Journal of Broadcasting and Electronic Media, 51, 632-650.

Levy, M. R., \& Windahl, S. (1984). Audience activity and gratifications: A conceptual clarification and exploration. Communication Research, 11, 51-78.

Li, I., Dey, A., \& Forlizzi, J. (2010). A stage-based model of personal informatics systems. Proceedings of the SIGCHI Conference on Human Factors in Computing Systems. 557-566.

Maher, C., Ferguson, M., Vandelanotte, C., Plotnikoff, R., De Bourdeaudhuij, I., Thomas, S., Nelson-Field, K., \& Olds, T. (2015). A web-based, social networking physical activity intervention for insufficiently active adults delivered via Facebook app: randomized controlled trial. Journal of Medical Internet Research, 17(7), e174.

Malik, A., Dhir, A., \& Nieminen, M. (2016). Uses and gratifications of digital photo sharing on Facebook. Telematics and Informatics, 33(1), 129-138.

Marchand, A., \& Hennig-Thurau, T. (2013). Value creation in the video game industry: Industry economics, consumer benefits, and research opportunities. Journal of Interactive Marketing, 27(3), 141-157.

McGonigal, J. (2011). Reality is broken: Why games make us better and how they can change the world. Penguin.

Morschheuser, B., Hamari, J., Koivisto, J., \& Maedche, A. (2017). Gamified crowdsourcing: Conceptualization, literature review, and future agenda. International Journal of HumanComputer Studies, 106, 26-43.

Munson, S., Poole, E., Perry, D. B., \& Peyton, T. (2015). Gamification and health. In: Walz, S.P. (Ed.), The Gameful World: Approaches, Issues, Applications. MIT Press, Cambridge, London, pp. 597-623. 
Nambisan, S., \& Baron, R. A. (2009). Virtual customer environments: Testing a model of voluntary participation in value co-creation activities. Journal of Product Innovation Management, 26(4), 388-406.

Notani, A. S. (1998). Moderators of perceived behavioral control's predictiveness in the theory of planned behavior: A meta-analysis. Journal of Consumer Psychology, 7(3), 247-271.

Outdoor Industry Association. (2015). 2015 Outdoor Industry Association Annual Report. (accessed July 31, 2017), [available at https://outdoorindustry.org/2015-annual-report/].

Palmgreen, P. (1984). Uses and Gratifications: A Theoretical Perspective. In Communication Yearbook 8, ed. R.N. Bostrom. Beverly Hills, CA: Sage Publications, 61-72.

Palmgreen, P., Wenner, L. A., \& Rosengren, K. E. (1985). Uses and gratifications research: The past ten years. In K.E. Rosengren, L.A. Wenner, \& P. Palmgreen (Eds.), Media gratifications research: Current perspectives (pp. 11-37). Beverly Hills, CA: Sage.

Park, B.-W., \& Lee, K. C. (2011). An empirical analysis of online gamers' perceptions of game items: Modified theory of consumption values approach. Cyberpsychology, Behavior and Social Networking, 14(7/8), 453-459.

Patrick, H., \& Williams, G. C. (2012). Self-determination theory: Its application to health behavior and complementarity with motivational interviewing. International Journal of Behavioral Nutrition and Physical Activity, 9(18).

Peetz, J., Buehler, R., \& Britten, K. (2011). Only minutes a day: Reframing exercise duration affects exercise intentions and behavior. Basic and Applied Social Psychology, 33, 118-127.

Pereira, P., Duarte, E., Rebelo, F., \& Noriega, P. (2014). A review of gamification for healthrelated contexts. In: Marcus A. (eds) Design, User Experience, and Usability. User Experience Design for Diverse Interaction Platforms and Environments. pp. 742-753. Switzerland: Springer International Publishing.

Rauschnabel, P. A., Rossmann, A., \& tom Dieck, M. C. (2017). An adoption framework for mobile augmented reality games: The case of Pokémon Go. Computers in Human Behavior, 76, 276-286.

Reynolds, L., Sosik, V. S., \& Cosley, D. (2013). When Wii doesn't fit: How non-beginners react to Wii fit's gamification. Proceedings of the First International Conference on Gameful Design, Research, and Applications, 111-114. 
Rideout, V., Roberts, D., \& Foehr, U. G. (2005). Generation M: Media in the lives of 8-18 year olds. Menlo Park, CA: Kaiser Family Foundation.

Riva, S., Camerini, A. -L., Allam, A., \& Schulz, P. J. (2014). Interactive sections of an Internetbased intervention increase empowerment of chronic back pain patients: Randomized controlled trial. Journal of Medical Internet Research, 16(8), e180.

Roberts, G. C. (2001). Understanding the dynamics of motivation in physical activity: The influence of achievement goals on motivational processes. In G. Roberts (Ed.), Advances in motivation in sport and exercise (pp. 1-50). Champaign, IL: Human Kinetics.

Rubin, A. M. (2002). The uses-and-gratifications perspective of media effects. Hillsdale, NJ: Erlbaum.

Sawh, M. (2016). Fitness app buyouts: Why sports brands are spending big bucks. Wareable. Available at https://www.wareable.com/fitness-trackers/fitness-app-buyouts-has-anythingreally-changed (Accessed 09.05.2018).

Sheth, J. N., Newman, B. I., \& Gross, B. L. (1991). Why we buy what we buy: A theory of consumption values. Journal of Business Research, 22, 159-170.

Spillers, F., \& Asimakopoulos, S. (2014). Does social user experience improve motivation for runners? In: Marcus A. (eds) Design, User Experience, and Usability. User Experience Design Practice. DUXU 2014. Lecture Notes in Computer Science, vol 8520. Springer, Cham.

Stafford, T. E., Stafford, M. R., \& Schkade, L. L. (2004). Determining uses and gratifications for the Internet. Decision Sciences, 35(2), 259-288.

Thorsteinsen, K., Vitters $\varnothing$, J., \& Svendsen, G. B. (2014). Increasing physical activity efficiently: An experimental pilot study of a website and mobile phone intervention. International Journal of Telemedicine and Applications, ID 746232.

van Doorn, J., Lemon, K. N., Mittal, V., Nass, S., Pick, D., Pirner, P., \& Verhoef, P. C. (2010). Customer engagement behavior: Theoretical foundations and research directions. Journal of Service Research, 13(3), 253-266.

Vargo, S., \& Lusch, R. (2008). Service-dominant logic: Continuing the evolution. Journal of the Academy of Marketing Science, 36(1), 1-10.

Venkatesh, V., Morris, M. G., Davis, G. B., \& Davis, F. D. (2003). User acceptance of information technology: Toward a unified view. MIS Quarterly, 27(3), 425-478. 
Venkatesh, V., Thong, J. Y. L., \& Xu, X. (2012). Consumer acceptance and use of information technology: Extending the unified theory of acceptance and use of technology. MIS Quarterly, 36(1), 157-178.

Wasko, M. M., \& Faraj, S. (2000). Why people participate and help others in electronic communities of practice. Journal of Strategic Information Systems, 9, 155-173.

Wei, P. S., \& Lu, H. P. (2014). Why do people play mobile social games? An examination of network externalities and of uses and gratifications. Internet Research, 24(3), 313-331.

Weibull, L. (1985). Structural factors in gratifications research. In K. E. Rosengren, L. A. Wenner, \& P. Palmgreen (Eds.), Media gratifications research: Current perspectives (pp. 123-147). Sage: Beverly Hills, CA, USA.

Wolf, G. I. (2009). Quantified self. Available at: http://web.archive. org/web/2009110094426/http://aether.com/quantifiedself (Accessed 5.12. 2016).

Wu, J. H., Wang, S. C., \& Tsai, H. H. (2010). Falling in love with online games: The uses and gratifications perspective. Computers in Human Behavior, 26(6), 1862-1871.

Yau, O. H. (1986). Chinese cultural values and their marketing implications. In: Hseh, R. T., Scherling, S. A. (Eds.), Proceeding of the Academy of International Business Southeast Asia Regional Conference. National Chiao Tung University, Taipei.

Yee, N. (2006). Motivations for play in online games. CyberPsychology \& Behavior, 9, 772-775. 
Table 1. Descriptive statistics and correlations of variables $(N=5,072)$.

\begin{tabular}{|c|c|c|c|c|c|c|c|c|c|c|c|c|c|c|c|}
\hline & Min & Mean & Max & SD & 1 & 2 & 3 & 4 & 5 & 6 & 7 & 8 & 9 & 10 & 11 \\
\hline 1. Purchases (sales) & 1.00 & 2.72 & 58.00 & 3.07 & 1 & & & & & & & & & & \\
\hline 2. Purchases (revenue) & 1.00 & 147.20 & 4490.00 & 239.12 & $0.81 * *$ & 1 & & & & & & & & & \\
\hline 3. Engagement & 0.00 & 85.75 & 1664.00 & 121.21 & $0.27 * *$ & $0.25^{* *}$ & 1 & & & & & & & & \\
\hline 4. Epistemic benefits & 0.00 & 49.75 & 7203.00 & 196.57 & $0.15^{* *}$ & $0.13^{* *}$ & $0.27 * *$ & 1 & & & & & & & \\
\hline 5. Social integrative benefits & 0.00 & 3.69 & 574.00 & 19.59 & $0.22 * *$ & $0.19^{* *}$ & $0.22 * *$ & $0.14 * *$ & 1 & & & & & & \\
\hline 6. Personal integrative benefits & 0.00 & 2121.03 & 38415.00 & 3270.27 & $0.19 * *$ & $0.18^{* *}$ & $0.67 * *$ & $0.18 * *$ & $0.18 * *$ & 1 & & & & & \\
\hline 7. Age & 15.00 & 47.86 & 78.00 & 7.68 & $0.11 * *$ & $0.08^{* *}$ & $0.19 * *$ & 0.01 & $0.04 * *$ & $0.15^{* *}$ & 1 & & & & \\
\hline 8. Experience & 730.00 & 1065.56 & 1689.00 & 187.59 & $0.07 * *$ & $0.07 * *$ & $0.06 * *$ & $0.18 * *$ & $0.06 * *$ & $0.10 * *$ & $0.02 * *$ & 1 & & & \\
\hline 9. Exercise duration & 0.00 & 17.41 & 1416.00 & 28.35 & $-0.04 *$ & -0.01 & $-0.07 * *$ & $-0.04 * *$ & -0.02 & $0.09 * *$ & -0.02 & $-0.04 * *$ & 1 & & \\
\hline 10. Habit & 0.00 & 0.07 & 3.00 & 0.28 & $0.15^{* *}$ & $0.14 * *$ & $0.61 * *$ & $0.20 * *$ & $0.15 * *$ & $0.58 * *$ & $0.09 * *$ & 0.01 & $-0.06 * *$ & 1 & \\
\hline 11. Variety & 1.00 & 2.43 & 5.00 & 1.03 & $0.16^{* *}$ & $0.14 * *$ & $0.34 * *$ & $0.16 * *$ & $0.14 * *$ & $0.41 * *$ & $-0.04 * *$ & $0.15 * *$ & $-0.07 * *$ & $0.25 * *$ & 1 \\
\hline
\end{tabular}

* Significant at 0.05 (2-tailed).

** Significant at 0.01 (2-tailed). 
Table 2. Descriptive statistics of exercise behavior $(N=5,072)$.

\begin{tabular}{|c|c|c|c|c|c|}
\hline & Mean & Min & Median & Max & SD \\
\hline \multicolumn{6}{|c|}{ Total exercise volume during subscription period } \\
\hline Total & 160.601 & 1.000 & 74.000 & 2828.000 & 257.494 \\
\hline Hiking & 69.521 & 0.000 & 29.000 & 1058.000 & 108.125 \\
\hline Walking & 51.406 & 0.000 & 4.000 & 2257.000 & 152.763 \\
\hline Bicycling & 31.426 & 0.000 & 1.000 & 1502.000 & 97.214 \\
\hline Jogging & 8.118 & 0.000 & 0.000 & 1659.000 & 53.164 \\
\hline Rollerblading & 0.130 & 0.000 & 0.000 & 239.000 & 3.740 \\
\hline \multicolumn{6}{|c|}{ Average exercise volume per month } \\
\hline Total & 4.637 & 0.020 & 2.180 & 79.520 & 7.230 \\
\hline Hiking & 2.027 & 0.000 & 0.825 & 34.150 & 3.144 \\
\hline Walking & 1.472 & 0.000 & 0.120 & 57.710 & 4.261 \\
\hline Bicycling & 0.898 & 0.000 & 0.030 & 40.590 & 2.731 \\
\hline Jogging & 0.237 & 0.000 & 0.000 & 50.270 & 1.538 \\
\hline Rollerblading & 0.004 & 0.000 & 0.000 & 6.830 & 0.106 \\
\hline
\end{tabular}


Table 3. Results of regression model (Model A: Engagement).

\begin{tabular}{llll}
\hline Variable & $\begin{array}{l}\text { Parameter } \\
\text { estimate }\end{array}$ & Standard error & t-value \\
\hline Intercept & 0.000 & 0.009 & 0.000 \\
Epistemic benefits & 0.265 & 0.016 & $16.139^{* * *}$ \\
Social integrative benefits & 0.050 & 0.012 & $4.185^{* * *}$ \\
Personal integrative benefits & 0.436 & 0.014 & $32.283^{* * *}$ \\
Age & 0.099 & 0.009 & $10.465^{* * *}$ \\
Experience & -0.048 & 0.010 & $-4.917^{* * *}$ \\
Epistemic benefits $\times$ Age & 0.024 & 0.010 & $2.361^{*}$ \\
Epistemic benefits $\times$ Experience & -0.179 & 0.017 & $-10.804^{* * *}$ \\
Social integrative benefits $\times$ Age & 0.006 & 0.011 & 0.568 \\
Social integrative benefits $\times$ Experience & 0.017 & 0.011 & 1.528 \\
Personal integrative benefits $\times$ Age & 0.023 & 0.010 & $2.223^{*}$ \\
Personal integrative benefits $\times$ Experience & -0.032 & 0.010 & $-3.256^{* *}$ \\
Exercise duration & -0.077 & 0.009 & $-8.145^{* * *}$ \\
Habit & 0.278 & 0.012 & $23.748^{* * *}$ \\
Variety & 0.062 & 0.010 & $5.905^{* * *}$ \\
\hline
\end{tabular}

Note: $\mathrm{N}=5,072, \mathrm{~F}=477 * * *, \mathrm{R}^{2}=0.569$, Adjusted $\mathrm{R}^{2}=0.568$.

* Significant at 0.05 .

** Significant at 0.01 .

$* * *$ Significant at 0.001 . 
Table 4. Results of regression model (Model B1: Sales).

\begin{tabular}{llll}
\hline Variable & $\begin{array}{l}\text { Parameter } \\
\text { estimate }\end{array}$ & Standard error & t-value \\
\hline Intercept & 0.000 & 0.013 & 0.000 \\
Epistemic benefits & 0.089 & 0.024 & $3.721^{* * *}$ \\
Social integrative benefits & 0.164 & 0.017 & $9.514^{* * *}$ \\
Personal integrative benefits & -0.021 & 0.021 & -0.983 \\
Age & 0.068 & 0.014 & $4.971^{* * *}$ \\
Experience & 0.020 & 0.014 & 1.439 \\
Epistemic benefits $\times$ Age & 0.020 & 0.014 & 1.404 \\
Epistemic benefits $\times$ Experience & -0.052 & 0.024 & $-2.194 *$ \\
Social integrative benefits $\times$ Age & -0.080 & 0.016 & $-5.146^{* * *}$ \\
Social integrative benefits $\times$ Experience & 0.073 & 0.016 & $4.681^{* * *}$ \\
Personal integrative benefits $\times$ Age & 0.003 & 0.015 & 0.232 \\
Personal integrative benefits $\times$ Experience & 0.023 & 0.014 & 1.635 \\
Exercise duration & -0.009 & 0.014 & -0.656 \\
Habit & -0.018 & 0.018 & -1.050 \\
Variety & 0.066 & 0.015 & $4.394^{* * *}$ \\
Engagement & 0.198 & 0.020 & $9.874^{* * *}$ \\
\hline
\end{tabular}

Note: $\mathrm{N}=5,072, \mathrm{~F}=46.44 * * *, \mathrm{R}^{2}=0.121$, Adjusted $\mathrm{R}^{2}=0.119$.

* Significant at 0.05 .

** Significant at 0.01 .

$* * *$ Significant at 0.001 . 
Table 5. Results of regression model (Model B2: Revenue).

\begin{tabular}{llll}
\hline Variable & $\begin{array}{l}\text { Parameter } \\
\text { estimate }\end{array}$ & Standard error & t-value \\
\hline Intercept & 0.000 & 0.013 & 0.000 \\
Epistemic benefits & 0.065 & 0.024 & $2.681^{* *}$ \\
Social integrative benefits & 0.146 & 0.017 & $8.374 * * *$ \\
Personal integrative benefits & -0.035 & 0.022 & -1.627 \\
Age & 0.044 & 0.014 & $3.170^{* *}$ \\
Experience & 0.030 & 0.014 & $2.155^{*}$ \\
Epistemic benefits $\times$ Age & 0.017 & 0.014 & 1.208 \\
Epistemic benefits $\times$ Experience & -0.038 & 0.024 & -1.551 \\
Social integrative benefits $\times$ Age & -0.070 & 0.016 & $-4.470^{* * *}$ \\
Social integrative benefits $\times$ Experience & 0.050 & 0.016 & $3.177^{* *}$ \\
Personal integrative benefits $\times$ Age & 0.018 & 0.015 & 1.219 \\
Personal integrative benefits $\times$ Experience & 0.031 & 0.014 & $2.165^{*}$ \\
Exercise duration & 0.019 & 0.014 & 1.373 \\
Habit & -0.009 & 0.018 & -0.499 \\
Variety & 0.063 & 0.015 & $4.168^{* * *}$ \\
Engagement & 0.192 & 0.020 & $9.431^{* * *}$ \\
\hline
\end{tabular}

Note: $\mathrm{N}=5,072, \mathrm{~F}=35.6^{* * *}, \mathrm{R}^{2}=0.096$, Adjusted $\mathrm{R}^{2}=0.093$.

* Significant at 0.05 .

** Significant at 0.01 .

$* * *$ Significant at 0.001 . 


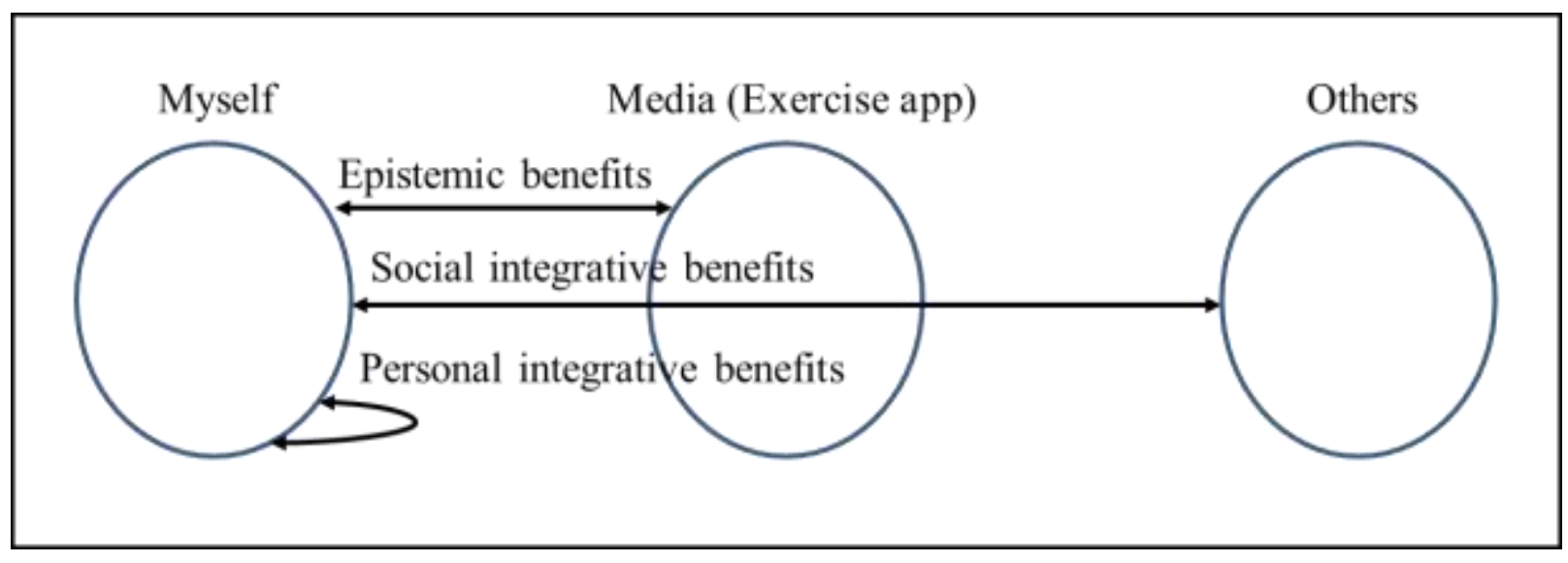

Figure 1. Customer use-and-gratification benefits in exercise app use.

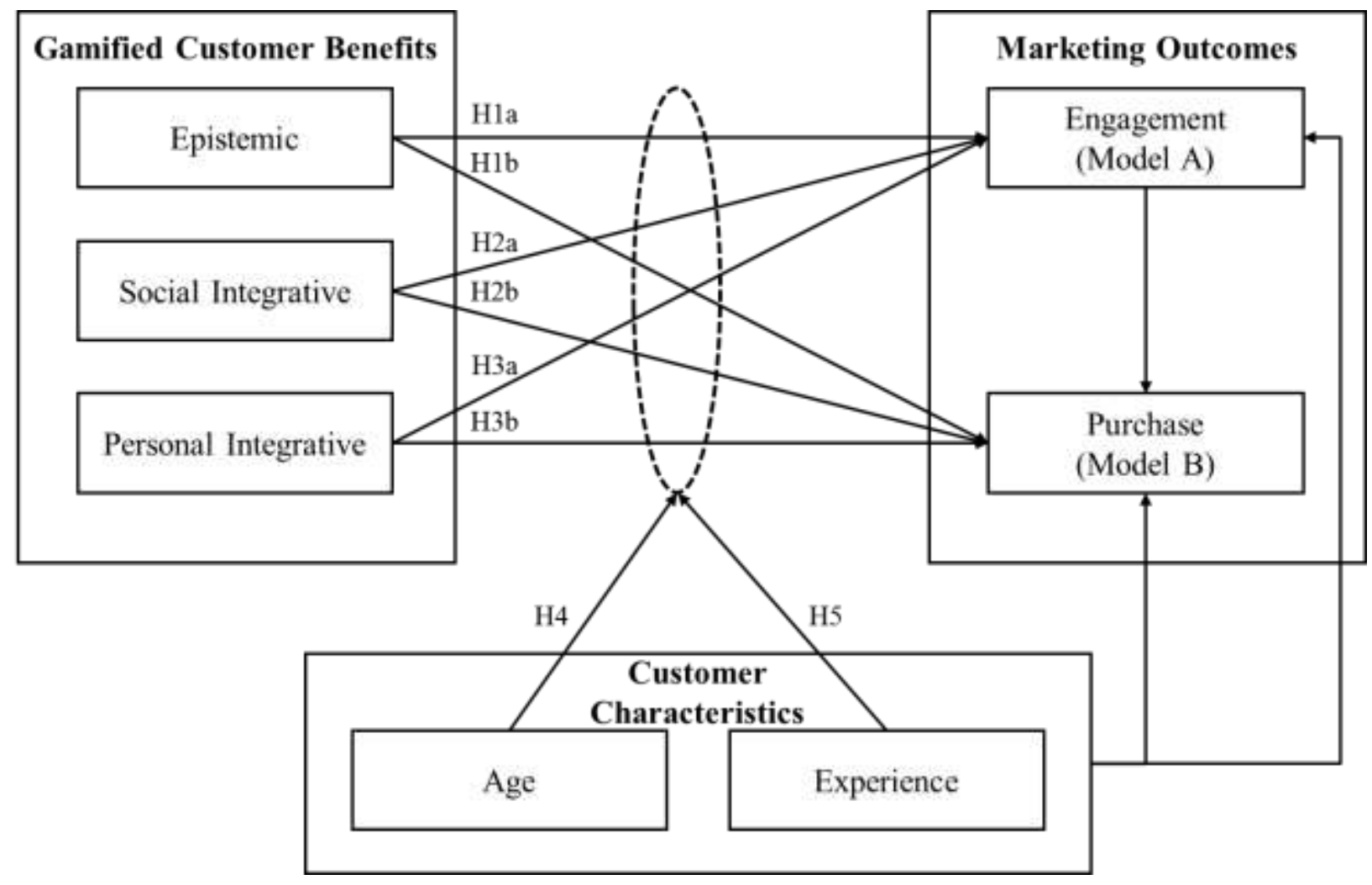

Figure 2. Research model and hypotheses. 